Issued by Sandia National Laboratories, operated for the United States Department of Energy by Sandia Corporation.

NOTICE: This report was prepared as an account of work sponsored by an agency of the United States Government. Neither the United States Government, nor any agency thereof, nor any of their employees, nor any of their contractors, subcontractors, or their employees, make any warranty, express or implied, or assume any legal liability or responsibility for the accuracy, completeness, or usefulness of any information, apparatus, product, or process disclosed, or represent that its use would not infringe privately owned rights. Reference herein to any specific commercial product, process, or service by trade name, trademark, manufacturer, or otherwise, does not necessarily constitute or imply its endorsement, recommendation, or favoring by the United States Government, any agency thereof, or any of their contractors or subcontractors. The views and opinions expressed herein do not necessarily state or reflect those of the United States Government, any agency thereof, or any of their contractors.

Printed in the United States of America. This report has been reproduced directly from the best available copy.

Available to DOE and DOE contractors from

Office of Scientific and Technical Information

P.O. Box 62

Oak Ridge, TN 37831

Prices available from (703) 605-6000

Web site: http://www.ntis.gov/ordering.htm

Available to the public from

National Technical Information Service

U.S. Department of Commerce

5285 Port Royal Rd

Springfield, VA 22161

NTIS price codes

Printed copy: A03

Microfiche copy: A01

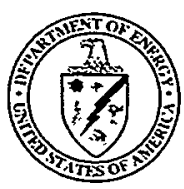




\section{DISCLAIMER}

Portions of this document may be illegible in electronic image products. Images are produced from the best available original document. 
SAND99-0921

Unlimited Release

Printed July 1999

\title{
Selective Oxidation Technology and its Applications toward Electronic
}

\author{
and Optoelectronic Devices
}

Olga B. Spahn, Andrew A. Allerman, Kent D. Choquette, Gregory A. Vawter, John F. Klem, Charles T. Sullivan, John P. Sullivan, Carol I. Ashby, Arlee V. Smith, Thomas D.

Raymond, William J. Alford

Center for Compound Semiconductor Science and Technology

Sandia National Laboratories

P. O. Box 5800

Albuquerque, NM 87185-0603

\begin{abstract}
Selective oxidation of AlGaAs compounds has facilitated dramatic improvements in the performance of near IR VCSELs. Under the auspices of this proposal we have: (1) expanded our understanding of both the strengths and the limitations of this technology; (2) explored its applicability to other $\mathrm{Al}$ bearing materials; (3) utilized this technology base to demonstrate a variety of new electronic and optoelectronic devices; and (4) established the reliability and manufacturability of oxidized devices such as VCSELs. Specifically, we have investigated conditions required to maximize control of the oxidation process as well as those required to facilitate/inhibit etching of the resultant oxide. Concurrently, studies were performed to extend the technology to other Albearing compounds such as $\mathrm{Al}(\mathrm{Ga}) \mathrm{AsSb}$, In $\mathrm{Al}(\mathrm{Ga}) \mathrm{P}$ and $\mathrm{Al}(\mathrm{Ga}) \mathrm{N}$. Several new devices utilizing the selective oxidation technology of $\mathrm{AlGaAs}$, as well as $\mathrm{Al}(\mathrm{Ga}) \mathrm{AsSb}$ were be considered. On a separate front, we also explored the possibility of using oxidized $\mathrm{AlGaAs}$ and $\mathrm{InAl}(\mathrm{Ga}) \mathrm{P}$ to form $\mathrm{GaAs} / \mathrm{AlGaAs}$ FETs. Finally, reliability and manufacturability issues of the high performance VCSELs fabricated using selective oxidation technology, were addressed.
\end{abstract}




\section{Contents}

1. Introduction

2. Oxidation of AlGaAs

3. Oxidation of AlGaAs for VCSEL and waveguides

4. Oxidation of AlGaAs for MISFET applications

5. Oxidation of other Al-bearing III-V materials

6. Conclusion 


\section{Introduction}

This LDRD project was directed toward study of the selective, steam oxidation process of Al-bearing III-V compounds, most significantly AlGaAs grown on GaAs. We have extracted temperature, time and $\mathrm{Al}$ mole fraction dependence of this process, as well as noted dependence on other variables such as layer thickness, carrier gas, adjacent layer thickness and others. We have applied this knowledge to engineer VCSELs that utilize the oxidized layer as a current constriction. We have obtained excellent results in terms of threshold current and wall plug efficiency of these devices. Finally, reliability and manufacturability issues of the high performance VCSELs fabricated using selective oxidation technology, was addressed

In addition, layers of oxidized $\mathrm{AlGaAs}$ were investigated as a means of forming various optical elements, such as convex and concave lenses that could be embedded into an assortment of surface normal, multilayer devices. Oxidized $\mathrm{AlGaAs}$ was also investigated for integration into waveguides, in particular as a means of inducing very large form birefringence. We have investigated the utility of application of to MOSFET devices and discovered some limitations of the oxidation process, which may limit its use for this type of application.

Furthermore, other III-V compounds, which contain Al, have been studied as candidates for oxidation. In particular, we have oxidized $\mathrm{AlGaAsSb}$ on InP substrates and noted a novel and distinct oxidation process, which resulted in formation of the Al-oxide as well as a semi-metallic $\mathrm{Sb}$ layer.

\section{Oxidation of AlGaAs}

In the recent years, there has been a great deal activity in the area of oxidation of Albearing III-V compounds, especially AlGaAs. Unlike Si, GaAs is not known to form stable oxides, such as $\mathrm{SiO} 2$. The fact that $\mathrm{Si}$ forms a stable, uniform oxide is of great technological importance in the area of microfabrication. Similarly, the fact that oxides of GaAs are unstable (and poisonous) is one of the limitations of this material system in the area of microfabrication, especially microelectronics. However, GaAs is extensively used for optoelectronics and many have noticed reliability problems of devices due to a particular degradation of high $\mathrm{Al}$ mole fraction $\mathrm{AlGaAs}$ and formation of a native (gibbsite phase) oxide. Of course it was a highly undesirable phenomenon that needed to be understood in order to be corrected. Thus several workers set out to duplicate and speed up the natural degradation of AlGaAs in atmospheric conditions in order to understand it as far back as 1979. Then in 1990, a group from University of Illinois found that by exposing high $\mathrm{Al}$ mole fraction $\mathrm{AlGaAs}$ to a wet steam environment at elevated temperatures $\left(\sim 400^{\circ} \mathrm{C}\right)$ resulted in formation of a new type of $\mathrm{Al}$-oxide. This oxide was different from the type that forms naturally when AlGaAs is exposed to atmospheric conditions. It was chemically and mechanically stable, and thus useful in device fabrication. Other differences between the natural, atmospheric (gibbsite) oxide and the "steam" oxide include formation at an elevated temperature (near $400^{\circ} \mathrm{C}$ instead of room temperature), growth within minutes or hours rather than over a period of months and years and contraction rather than expansion upon formation. Finally, the "steam" oxide exhibits a low refractive index, on the order of 1.55 . 
To perform oxidation, first the layers to be oxidized must be exposed to the oxidation atmosphere. If this is to be a surface oxidation (i.e. proceeding perpendicular to the sample surface), no pre-processing is necessary assuming the top most layer is the one to be oxidized. If lateral oxidation is desired (i.e. proceeding parallel to the sample surface), mesas of the material must be etched, such that the sidewalls of layers to be oxidized are exposed. Then samples are put into an oxidation oven. The oxidation apparatus including the oven is shown in Figure 1. It consists of a tube furnace through which hot water vapor is carried by a carrier gas (usually $\mathrm{N}_{2}$ ). The furnace and the water bath are temperature controlled to ensure repeatability and consistency of the process.

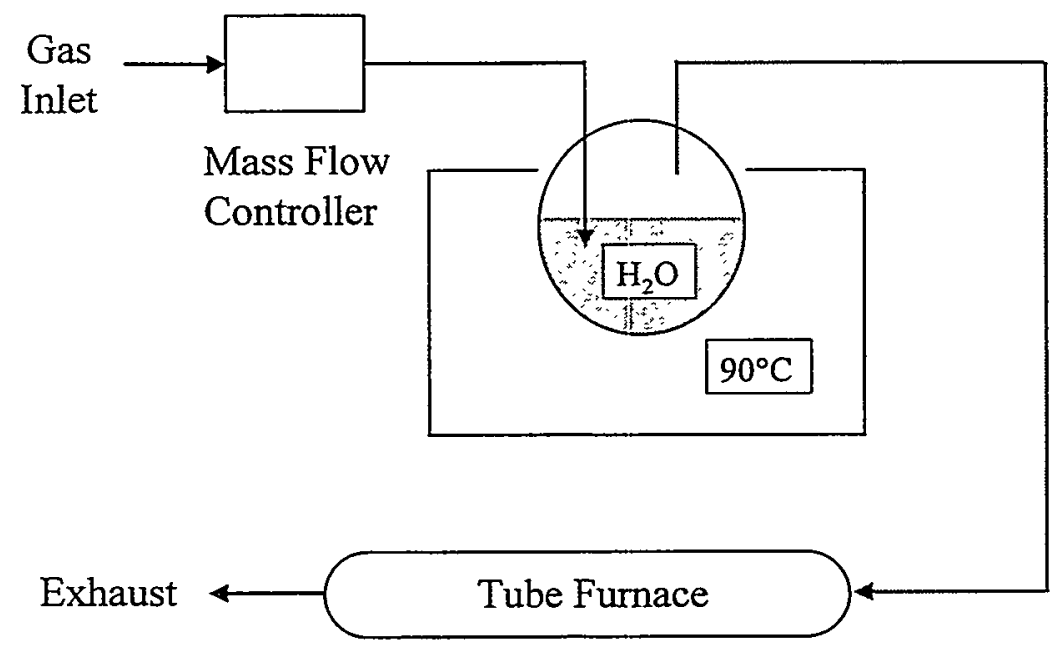

Figure 1. Oxidation apparatus

The chemical reaction consistent with the formation of the "steam" oxide can be written expressed as follows:

$$
\begin{array}{cl}
2 \mathrm{AlAs}+6 \mathrm{H}_{2} \mathrm{O}_{(\mathrm{g})}=\mathrm{Al}_{2} \mathrm{O}_{3}+\mathrm{As}_{2} \mathrm{O}_{3(\mathrm{l})}+6 \mathrm{H}_{2} & \Delta \mathrm{G}^{698}=-473 \mathrm{~kJ} / \mathrm{mol} \\
\mathrm{As}_{2} \mathrm{O}_{3(\mathrm{l})}+3 \mathrm{H}_{2}=2 \mathrm{As}+3 \mathrm{H}_{2} \mathrm{O}_{(\mathrm{g})} & \Delta \mathrm{G}^{698}=-131 \mathrm{~kJ} / \mathrm{mol} \\
\mathrm{As}_{2} \mathrm{O}_{3(\mathrm{l})}+6 \mathrm{H}=2 \mathrm{As}+3 \mathrm{H}_{2} \mathrm{O}_{(\mathrm{g})} & \Delta \mathrm{G}^{698}=-1226 \mathrm{~kJ} / \mathrm{mol}
\end{array}
$$

Where $\Delta \mathrm{G}^{698}$ refers to the Gibbs free energy at a temperature of $698 \mathrm{Kelvin}$. A negative free energy implies that the process is thermodynamically favored to occur and it should be noted that reactions described in equation (1)-(3) all have negative free energies at temperatures employed. Some note worthy features of the above reactions include intermediate formation of $\mathrm{As}_{2} \mathrm{O}_{3}$ and As. Raman studies indicate a relatively constant As Raman signal during oxidation, implying a balance between chemical reaction forming As (equations (2) and (3)) and loss of As. It is thought that $\mathrm{As}$ forms $\mathrm{AsH}_{3}$ with atomic hydrogen $\left(\Delta G^{698}=-471 \mathrm{~kJ} / \mathrm{mol}\right)$, however As itself is sufficiently volatile to remove itself from the oxide. However, the mechanism for removal of As from the oxide is not strong enough to remove all the As, since elemental As is found in or around the oxidized regions. This has grave consequences for the application of these oxides in the MOS area. 
Transmission electron microscope (TEM) studies of the oxide confirm that the oxide is a $\gamma$-phase $\mathrm{Al}_{2} \mathrm{O}_{3}$, although crystallization from the amorphous state maybe brought on by annealing or electron beam of the TEM.

Another interesting feature of the reaction chemistry is that replacement of AlAs by $\mathrm{GaAs}$ in equation (1) results in $\Delta \mathrm{G}^{698}=+10 \mathrm{~kJ} / \mathrm{mol}$, making it thermodynamically unfavorable. Thus one can expect that addition of even a minute amount of $\mathrm{Ga}$ to AlAs

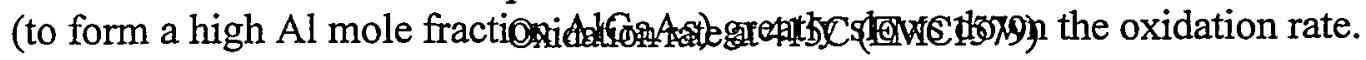

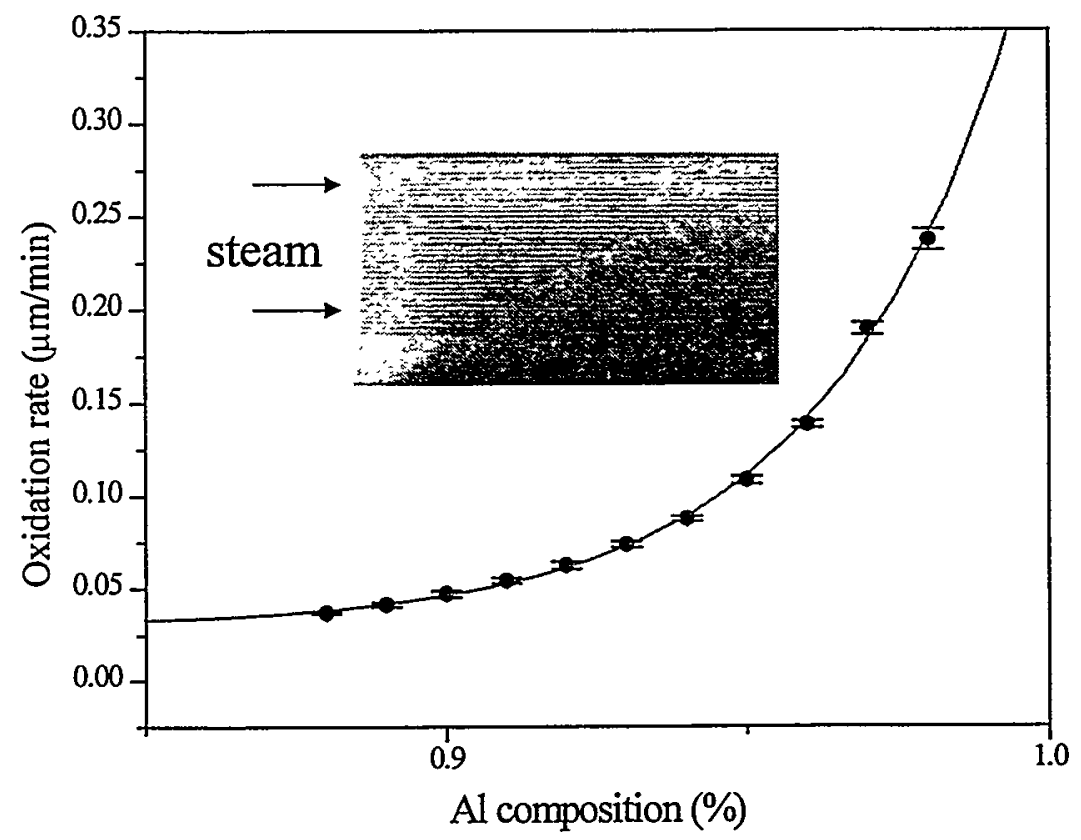

Figure 2 Oxidation rate of $\mathrm{AlGaAs}$ as a function of Al mole fraction Indeed, as shown in Figure 2, the oxidation rate of $\mathrm{Al}_{\mathrm{x}} \mathrm{Ga}_{1-\mathrm{x}} \mathrm{As}$ as a function of $\mathrm{x}$ drops precipitously as mole fraction of $\mathrm{Al}$ decreases from 1 . This property forms a basis for selective, lateral oxidation process, where by slight variation of the $\mathrm{Al}$ mole fraction in $\mathrm{AlGaAs}$, chosen layers may oxidize to a desired depth, whereas others do not oxidize much at all. In the regime of interest, the oxidation process proceeds with linear rates and no induction period and exhibits Arrhenius temperature dependence (see Figure 3).

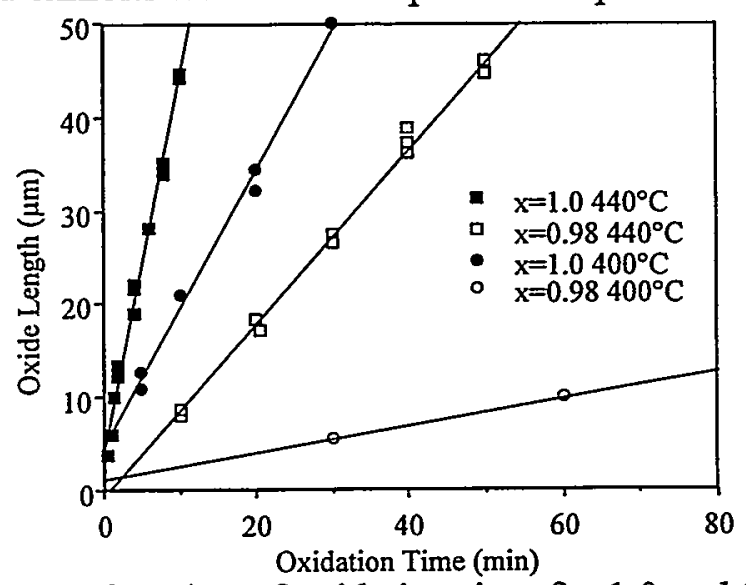

Figure 3 Oxide length as a function of oxidation time for 1.0 and $0.98 \mathrm{Al}$ mole fraction and two different oxidation temperatures $\left(400^{\circ} \mathrm{C}\right.$ and $\left.440^{\circ} \mathrm{C}\right)$. 
This regime assumes operation in a water vapor saturated regime, assuring that the reaction rates are not reactant limited. In our 4-inch diameter oven, a 3-1/min flow of $\mathrm{N}_{2}$ allows operation in that region. While most common carrier gas is $\mathrm{N}_{2}$, other gasses have been studied as well. Curiously, while there isn't much difference between $\mathrm{N}_{2}$, Ar or $3 \%$ $\mathrm{H}_{2}$ in $\mathrm{N}_{2}$, use of $\mathrm{O}_{2}$ as a carrier gas quenches oxidation completely. This most likely is related to the crucial role of hydrogen in removal of As from the oxide.

In addition to the strong dependence on temperature and $\mathrm{Al}$ mole fraction, the oxidation rate depends on the thickness of the layer to be oxidized, once that thickness drops below $80 \mathrm{~nm}$. This thickness dependence has been ascribed to Gibbs-Thomson effect, whereby the interfaces of the layers surrounding the oxidized layer exert pressure opposing formation of the new oxide. This results in a greater curvature of the oxidation terminus and slower oxidation rates in thin oxide layers. This property can also be used to an advantage in device fabrication by choosing appropriate layer thickness to control the extent of oxidation. Finally, it has been found that the oxidation rate can also be controlled by the thickness of the layers adjacent to the oxidized layer.

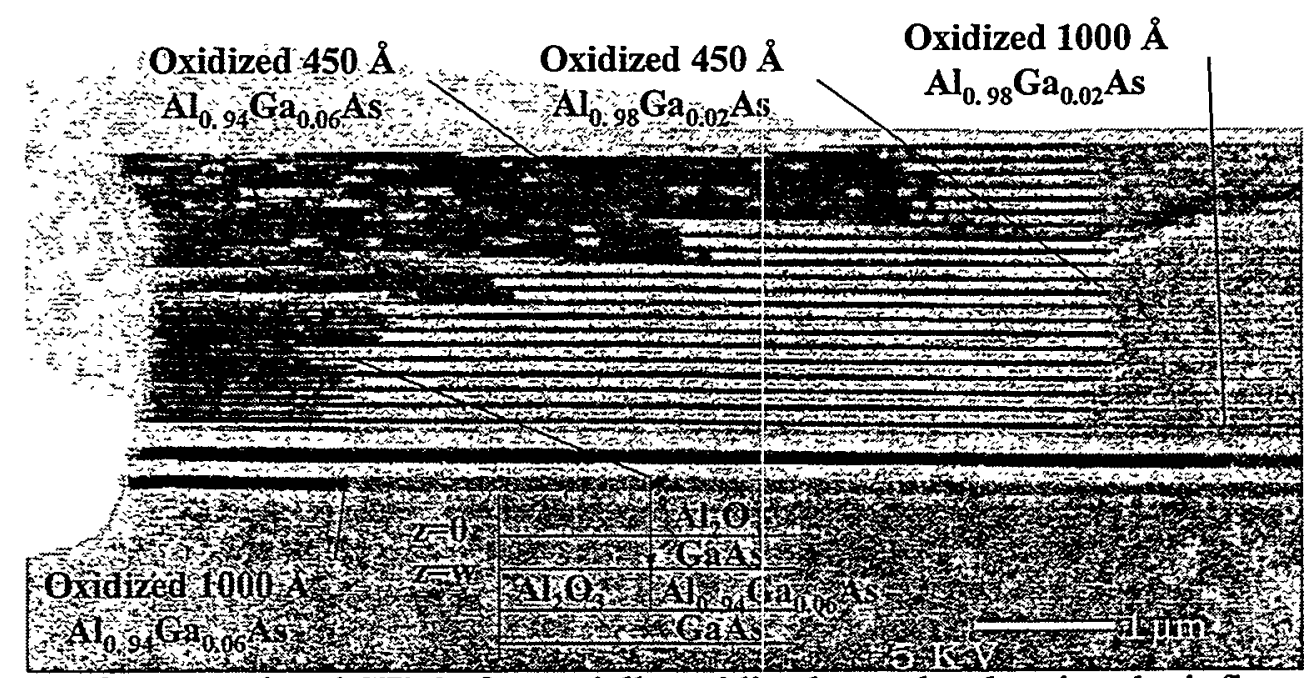

Figure 4 Cross sectional SEM of a partially oxidized sample, showing the influence of the thickness of $\mathrm{GaAs}$ barriers on the oxidation rate of the adjacent $\mathrm{AlGaAs}$ with $0.94 \mathrm{Al}$ mole fraction

Figure 4 shows a structure where $94 \%$ and $98 \% \mathrm{Al}$ containing $\mathrm{AlGaAs}$ layers are separated by different thickness GaAs layers. While $98 \%$ Al AlGaAs layers of the same thickness all oxidized to approximately same extent, the $94 \%$ layers oxidized further if they are separated from the $98 \%$ layers by thinner rather than thicker GaAs layers. This phenomenon is a result of the diffusion of the oxidant through a GaAs barrier to aid in the oxidation of the slower oxidizing $\mathrm{AlGaAs}$ layer, where the faster oxidizing $\mathrm{AlGaAs}$ layers serve as a feeder channel. Oxidation is a two-dimensional process, with the oxide forming in a lateral as well as transverse direction. By retarding oxidation in the transverse direction (with the use of low Al containing barriers) oxidation fronts of an arbitrary shape can be obtained. This property has been put to a use in fabrication of buried optical elements such as lenses. 


\section{Oxidation of AlGaAs for VCSELs and waveguides}

Optical properties of the oxides formed by steam oxidation of interest owing to their growing applications not just as an insulator, but as a low refractive index dielectric. One of the most important characteristics is the refractive index, which has been measured to be near 1.55. Another property of interest is the optical loss of the oxidized layers. While this is not particularly crucial in VCSELs, since the radiation propagates perpendicular to a small thickness of an oxide, it is of great interest in waveguide applications.

Transmission of the oxide layers has been characterized in the near infrared and infrared region has been measured. It shows a clear dip in transmission near $3 \mu \mathrm{m}$, which is associated with absorption due to $\mathrm{OH}$ groups in the oxide. Beyond that wavelength, $\mathrm{Al}-$ oxide appears to be fairly transparent out to $8-9 \mu \mathrm{m}$.

The infrared absorption of oxides is important in applications where oxide layers are used in nonlinear waveguide for difference frequency generation. Because of the large differential in the refractive index of the oxidized AlGaAs and un-oxidized AlGaAs or $\mathrm{GaAs}$, it is possible to induce a very large form birefringence in waveguides. This in turn allows a true phase match to occur for pump, signal and idler wavelengths, resulting in an appreciable efficiency of difference frequency generation. However, the issue of propagation losses in such oxidized waveguides remains important. We have fabricated some oxidized waveguides designed to phase match light at $950 \mathrm{~nm}, 1320 \mathrm{~nm}$ and 3450 $\mathrm{nm}$. Figure 5 shows a SEM of a partially oxidized waveguide cross section.

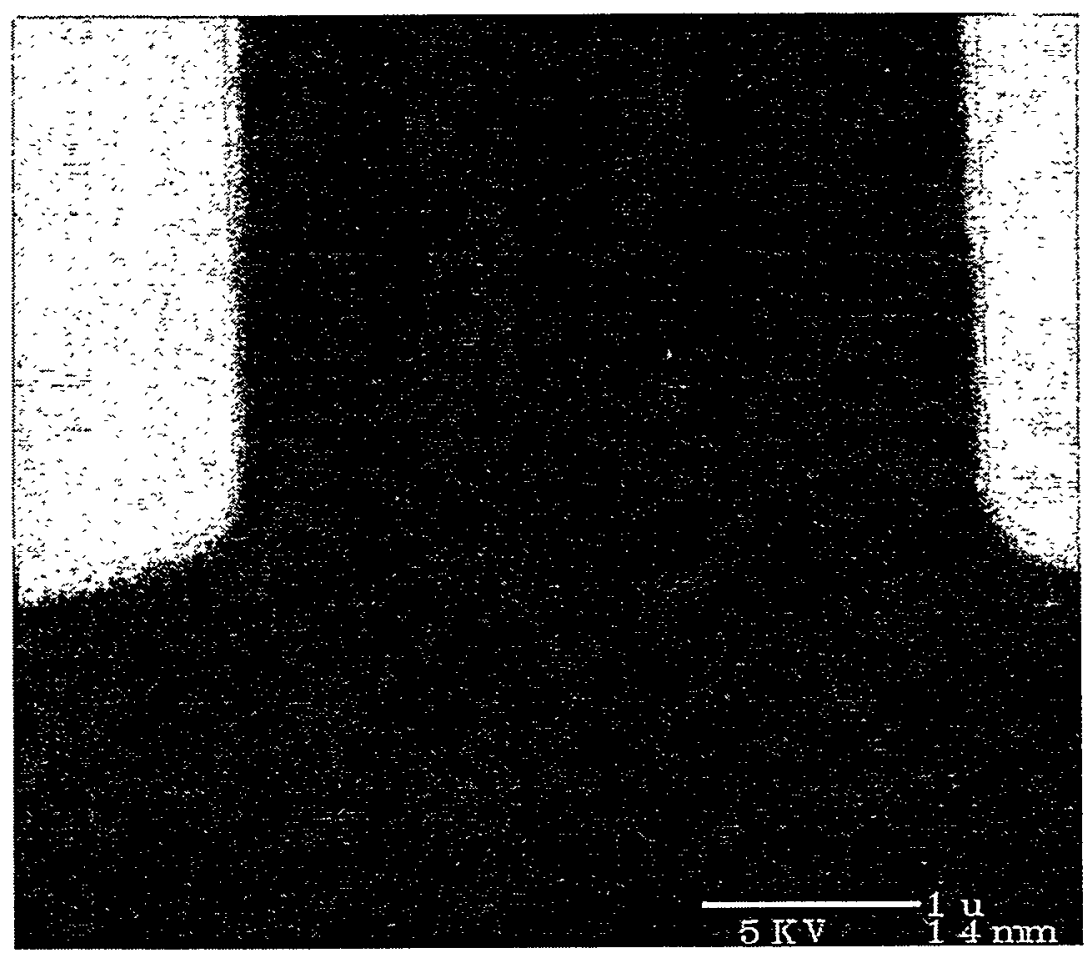

Figure 1. Cross sectional scanning electron microscope view of the partially oxidized waveguide. Dark areas are oxidized. 
Losses in the unoxidized guides have been measured at $6-7 \mathrm{~dB} / \mathrm{cm}$, while oxidized guides exhibit losses near 2-3 dB/cm. This is still somewhat high, but an encouraging result. The most common use of oxides in the waveguide devices, involves current confinement in EELs. In fact, the first devices utilizing the oxidized layers were EELs, where oxide acted to confine the current to the active region as well as provide an index guide. However, the most spectacular improvements in performance were brought about by application of oxides to VCSELs. Again, the oxidized layers were employed to provide current confinement, as shown in Figure 5.

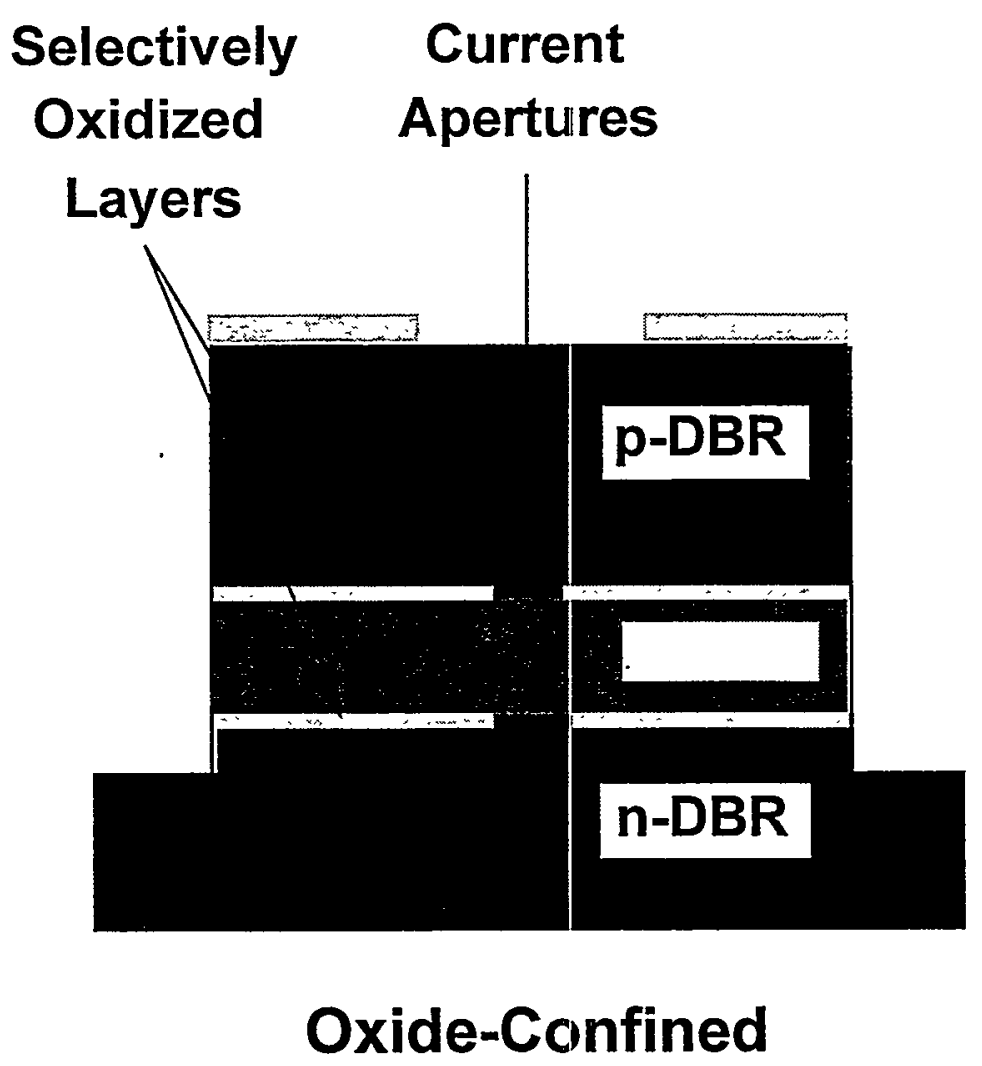

Figure 5 Schematic drawing of the current apertures formed by the oxidized layers in a VCSEL

Also, the thin oxide layer (aperture) placed next to the active region decreased optical losses, providing a measure of lateral confinement due to its low refractive index. This resulted in shrinkage of the active volume and loss reduction and thus a great reduction in the threshold current (breaking the $1 \mathrm{~mA}$ barrier). By appropriately tailoring the $\mathrm{Al}$ mole fraction of the layer to be oxidized, it is possible to oxidize only the confinement layers, without affecting the DBR layers or the active region. Thus a buried, dielectric aperture may be formed. By refining these concepts, VCSELs with oxide aperture soon demonstrated record high efficiency and low voltages in addition to low threshold currents, as shown in Figure 6. 


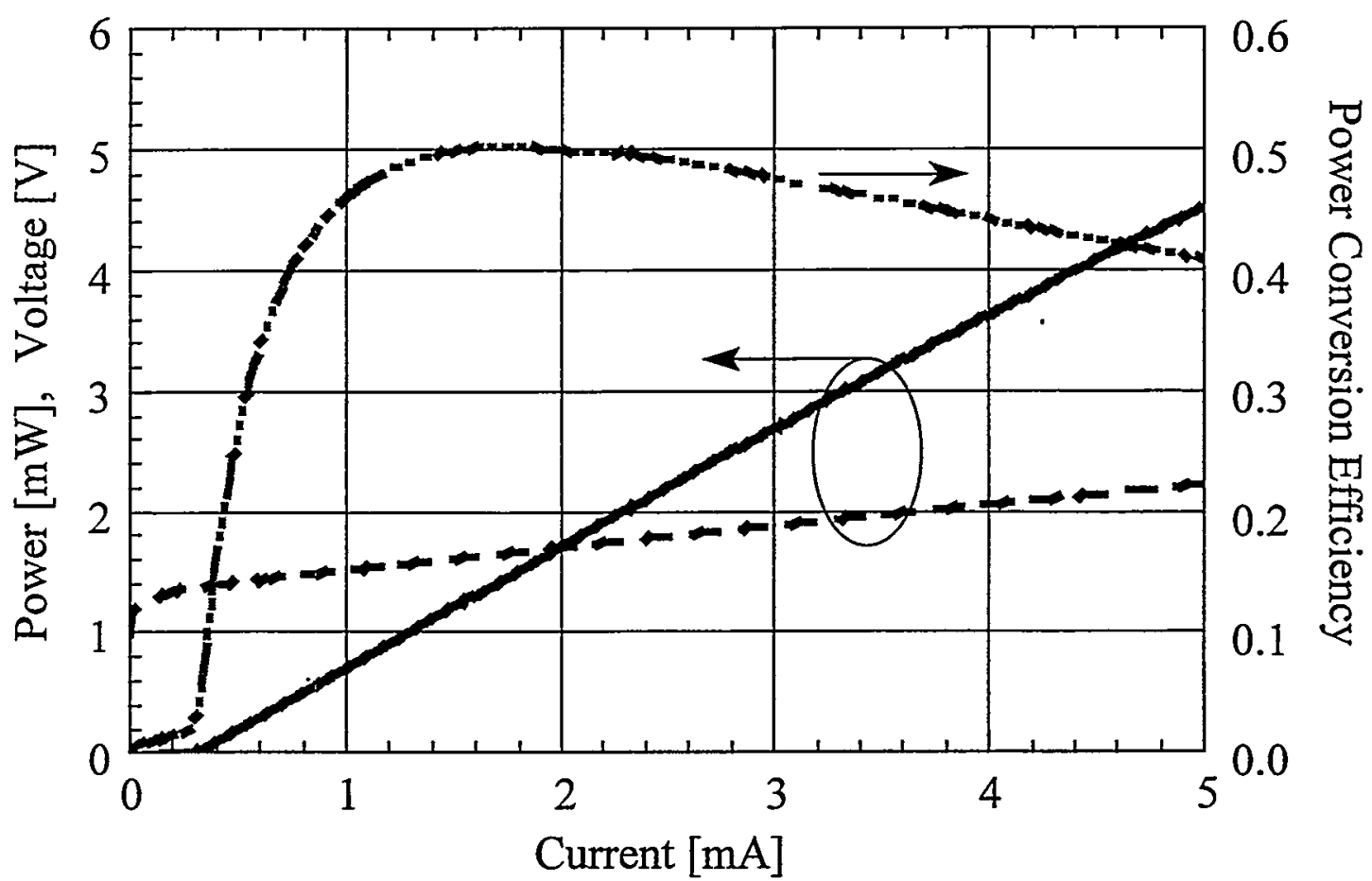

Figure 6 Power and voltage as function of injection current in an oxidized VCSEL

As mentioned previously, the ability to tailor the oxidation front by Al-mole fraction, thickness or barrier layer thickness variations has also been applied in devices. The use of tapered oxide apertures in VCSELs has lowered scattering loss even further.

Furthermore, buried optical elements such as lenses have also been fabricated using this method. Figure 7 shows a scanning electron micrograph of a cross section of such a buried lens.

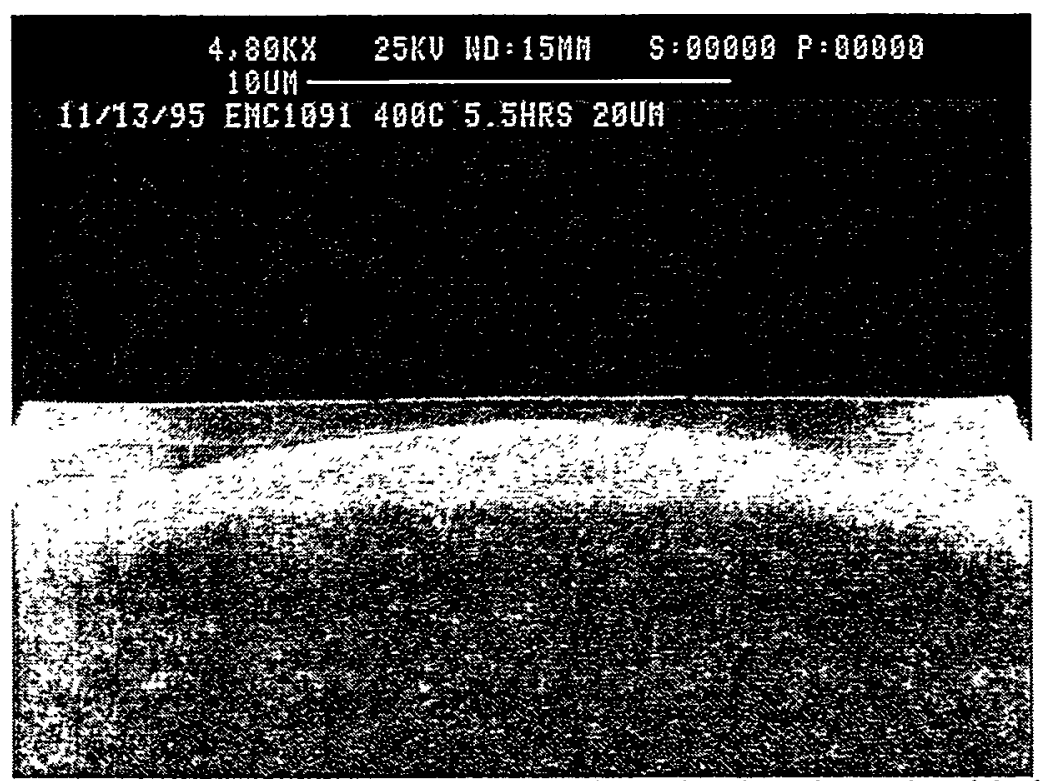

Figure 7 Cross sectional SEM of a lens formed by selective, lateral oxidation of AlGaAs 


\section{Oxidation of AlGaAs for MISFET}

Finally, oxides have been used in the electronic devices, as patterned by the Si devices. Figure 8 shows a schematic of a MISFET structure with a steam-oxide gate insulator. However the problem of As segregation and incomplete removal from the oxide results in interfacial state formation, which severely limits usefulness of the Al-oxides for this type of electronic applications. The presence of interfacial As and defects associated with its presence can also have a negative effect on optical properties of nearby quantum wells, thus positioning of the active region at least $20 \mathrm{~nm}$ from the oxidized layers is crucial .

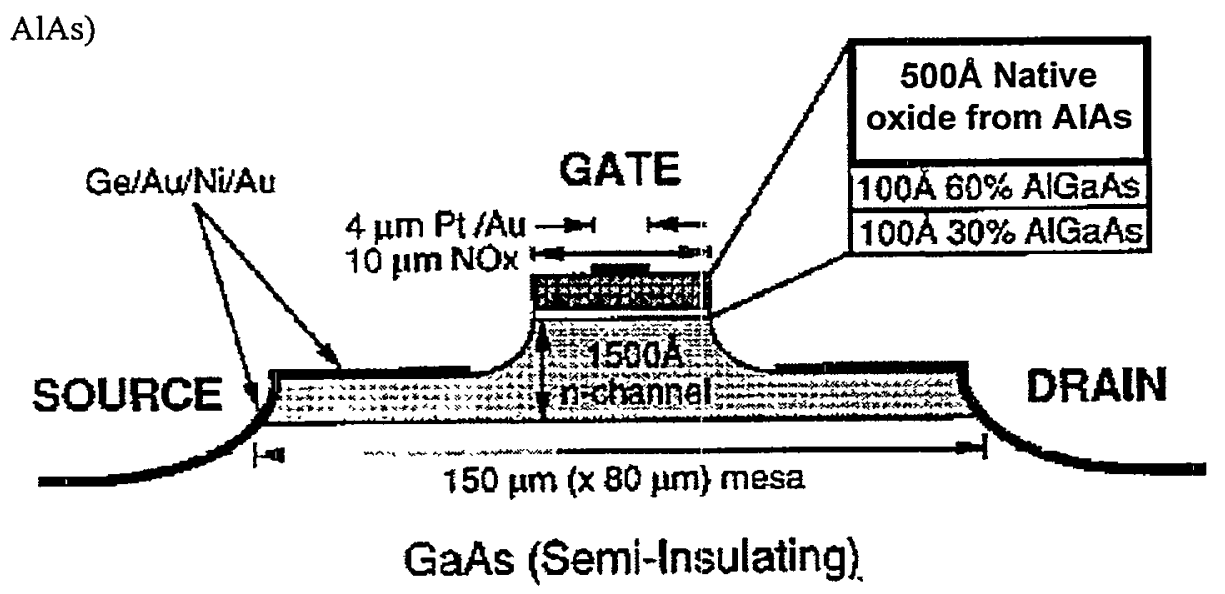

Figure 8 Schematic drawing of a MISFET with wet-oxide gate insulator

We have modeled how the production of large amounts of elemental As during the oxidation and its diffusion into adjacent regions can modify the properties of these regions in ways that impact device design, fabrication, and performance. The oxidation rate is determined primarily by the $\mathrm{Al}$ mole fraction, but the close proximity of a fasteroxidizing layer can produce a several-fold increase in oxidation rate for a layer of a given Al composition over the rate obtained with an isolated layer of the same composition. Injection of As interstitials into adjacent layers and the resulting development of defects, such as As antisite defects and group-III vacancies and interstitials, can alter the oxidation rate for nearby regions. Observed rate accelerations are consistent with the diffusion of As-generated defects from the fast-reaction layer to the slower-reaction layer. Our model based on the role of elemental As in such behavior as enhanced oxidation rates in close proximity to faster-oxidizing layers, the effect of relative layer thicknesses, and dependence of oxidation rate on position within the total structure provides a semiquantitative prediction of oxidation profile for complex structures.

During the third year of the LDRD program, an alternative strategy for reducing the interface state density of insulator-GaAs interfaces was explored. A sulfur-based wet chemical surface passivation treatment was applied to freshly etched GaAs surfaces prior to formation of the insulator layer. Early testing involved the use of a low temperature deposited insulator, silicon oxynitride, which was chosen in order to reduce the possibility of sulfur migration from the interface during insulator formation. Electrical measurements of metal-insulator-S-passivated GaAs structures revealed a strong 
electrical influence of the sulfur at the interface, however, it was not possible to deduce the amount of interface state reduction, due to the poor electrical properties of silicon oxynitride layers, which are known to have high defect trap densities.

\section{Oxidation of other Al-bearing III-V materials}

In addition to AlGaAs, other Al-bearing III-V compounds have been oxidized. For example, oxidation of AlAsSb has been demonstrated. Composition resulting in the lattice match to $\mathrm{InP}$ contains a $\mathrm{Al}$ mole fraction of 1 , since this material has a mixed column V composition (As and $\mathrm{Sb}$ ) and only one column III constituent. While even more readily oxidized than AlAs, this material forms Al-oxide (like AlAs) as well as an interfacial layer of semi-metallic $\mathrm{Sb}$. One could say that upon oxidation this semiconductor decomposes into a dielectric and a metal! It should be noted that the $\mathrm{Sb}$ layer does in fact exhibit a greatly reduced resistance as compared to an un-oxidized structure, as shown in Figure 9.

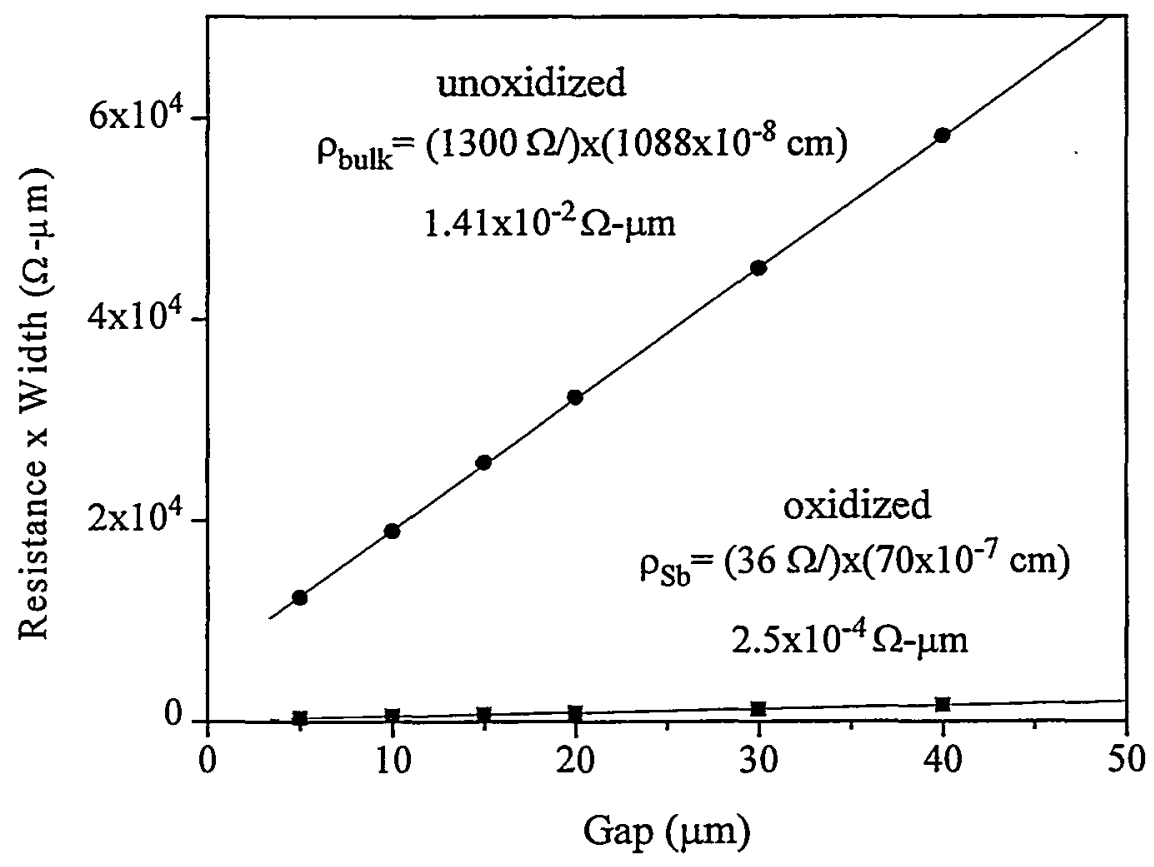

Figure 9 Transmission line measurements showing greatly reduced resitivity of an oxidized structure compared to an unoxidized structure

Figure 10 shows a cross sectional SEM of a partially and fully oxidized AlAsSb layer. Curiously, as the mole fraction of As is varied from 0 (AlSb) to 1 (AlAs), oxidation depth of AlAsSb varies dramatically (Figure 11). Largest depths are observed for As mole fractions corresponding to lattice match to InAs and GaSb substrates. These depths and the one for the composition resulting in lattice match to InP are quite a bit larger than the AlAs oxidation depth. However in absence of any As (AlSb), no oxidation at all is observed. Yet exposure to the steam environment at an elevated temperature, clearly 
alters the exposed side wall surface of AlSb, since no atmospheric oxidation occurs afterwards.

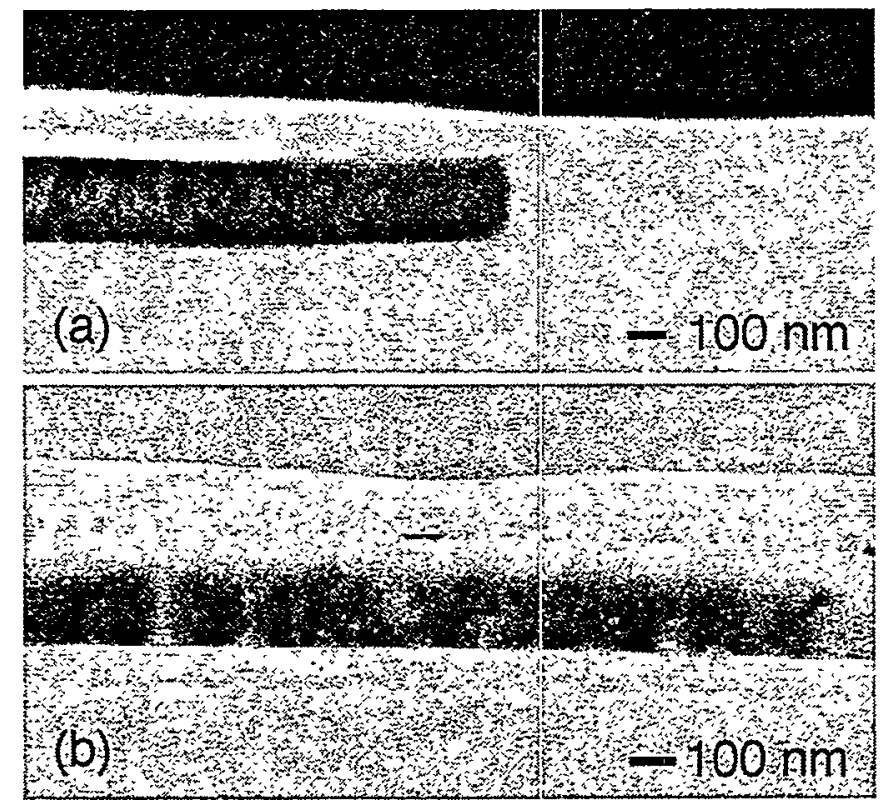

Figure 10 Cross sectional SEM of partially and fully oxidized AlAsSb layers. The dark areas are oxidized.

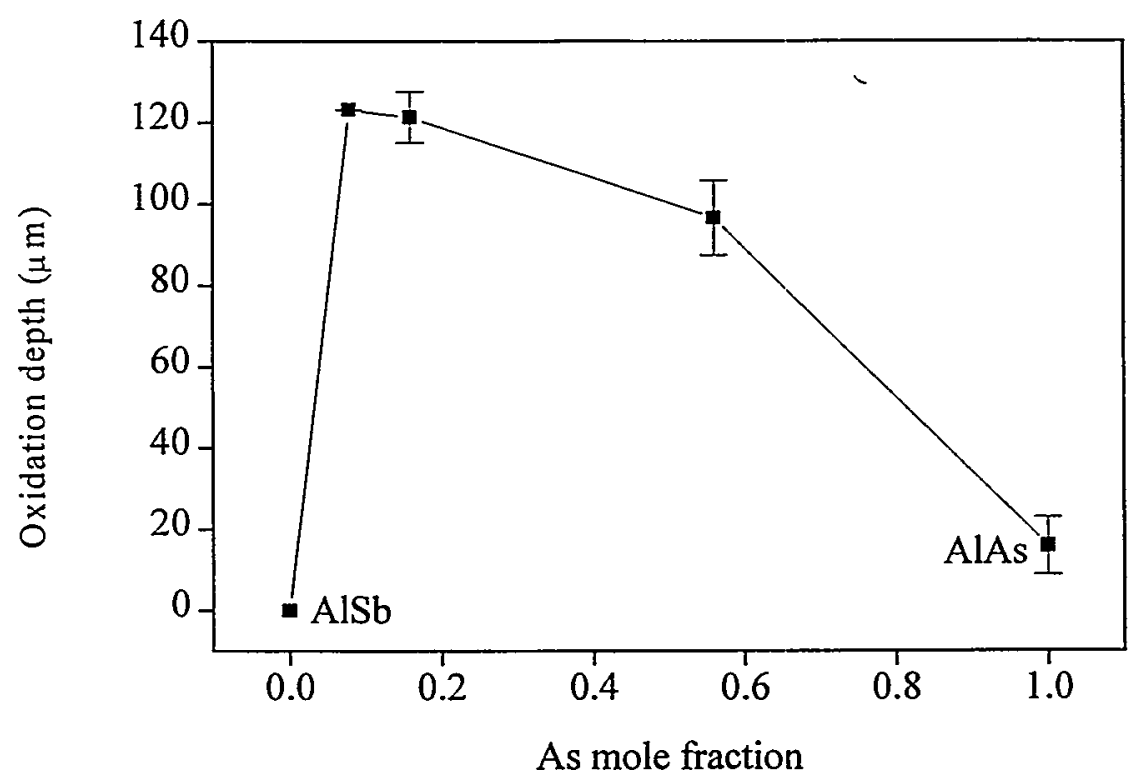

Figure 11 Oxidation depth as a function of As mole fraction for oxidation at $380^{\circ} \mathrm{C}$ for 20 minutes 


\section{Conclusion}

The area of oxidation of Al-bearing III-V compounds has experienced a great deal of growth in the past years. It has been shown to be a powerful concept in fabrication of optoelectronic devices in general and especially VCSELs. It has also been applied to waveguides and electronic devices such as MISFETs. Materials other AlGaAs are suitable for oxidation, although not necessarily with the same results. Problems associated with As precipitates await further investigation, since their presence limits utility of oxides in electronic applications.

Sandia is a multiprogram laboratory operated by Sandia Corporation, a Lockheed Martin Company, for the United States Department of Energy under Contract DE-AC04-04Al85000. 


$\begin{array}{lll}2 & \text { MS 0603 } & \text { Olga Blum (1712) } \\ 1 & \text { MS 0603 } & \text { Andy Allerman (1711) } \\ 1 & \text { MS 0603 } & \text { Kent Choquette (1712) } \\ 1 & \text { MS 0603 } & \text { Alan Vawter (1711) } \\ 1 & \text { MS 0603 } & \text { John Klem (1711) } \\ 1 & \text { MS 0603 } & \text { Charles Sullivan (1713) } \\ 1 & \text { MS 0603 } & \text { Mial Warren (1712) } \\ 1 & \text { MS 0603 } & \text { Peter Esherick (1711) } \\ 1 & \text { MS 0603 } & \text { Tom Zipperian (1713) } \\ 1 & \text { MS 0603 } & \text { Carol Ashby (1711) } \\ 1 & \text { MS 1421 } & \text { John Sullivan (1112) } \\ 1 & \text { MS 1421 } & \text { Wil Gauster (1112) } \\ 1 & \text { MS 1423 } & \text { Arlee Smith (1128) } \\ 1 & \text { MS 1423 } & \text { T.D. Raymond (1128) } \\ 1 & \text { MS 1423 } & \text { Joe Alford (1128) } \\ 1 & \text { MS 1423 } & \text { Gerry Hays (1128) } \\ 1 & \text { MS 9018 } & \text { Central Technical Files (8940-2) } \\ 2 & \text { MS 0899 } & \text { Technical Library (4916) } \\ 1 & \text { MS 0619 } & \text { Review \& Approval Desk (00111) } \\ 1 & \text { MS 0161 } & \text { Patent and Licensing Office (11500) } \\ 1 & & \text { For DOE/OSTI } \\ 1 & \text { MS 0188 } & \text { LDRD Office (4001) }\end{array}$

